Article type : Consensus Statement

\title{
International expert consensus guidance on indications, implementation and quality measures for Transanal Total Mesorectal Excision (TaTME)
}

On behalf of the TaTME Guidance group representing the ESCP (European Society of Coloproctology), in collaboration with ASCRS (American Society of Colon and Rectum Surgeons), ACPGBI (Association of Coloproctology of Great Britain and Ireland), ECCO (European Crohn's and Colitis Organisation), EAES (European Association of Endoscopic Surgeons), ESSO (European Society of Surgical Oncology), CSCRS (Canadian Society of Colorectal Surgery), CNSCRS (Chinese Society of Colorectal Surgery), CSLES (Chinese Society of Laparo-Endoscopic Surgery), CSSANZ (Colorectal Surgical Society of Australia and New Zealand), JSES (Japanese Society of Endoscopic Surgery), SACP (Argentinian Society of Coloproctology), SAGES (Society of American Gastrointestinal and Endoscopic Surgeons), SBCP (Brazilian Society of Coloproctology) and the Swiss-MIS (Swiss association for Minimally Invasive Surgery)

\section{Participants (in alphabetical order by surname):}

Michel Adamina, Felix Aigner, Sergio Araujo, Alberto Arezzo, Shady Ashamalla, Teresa deBecheAdams, Stephen Bell, Willem Bemelman, Carl Brown, Walter Brunner, Nicolas Buchs, Antonio Caycedo, Sami Chadi, Park Sung Chan, David Clark, Quentin Denost, André D'Hoore, Nicola Fearnhead, Nader Francis, Eelco de Graaf, Suguru Hasegawa, Julian Hayes, Alexander Heriot, Roel Hompes, Bert Houben, Masaaki Ito, Mark Katory, Jos Kleijnen, Werner Kneist, Joep Knol, Tsuyoshi Konishi, John Marks, Beatriz Martin-Perez, Justin Maykel, Elisabeth McLemore, Danilo Miskovic, Isacco Montroni Gabriela Möslein, Jae Hwan Oh, Rodrigo Oliva Perez, Marta Penna, Frederic Ris,

This is the author manuscript accepted for publication and has undergone full peer review but has not been through the copyediting, typesetting, pagination and proofreading process, which may lead to differences between this version and the Version of Record. Please cite this article as doi: 10.1111/CODI.15147

This article is protected by copyright. All rights reserved 
Gustavo Rossi, Eric Rullier, Gerald Seitinger, Antonino Spinelli, Andrew Stevenson, Patricia Sylla, Ichiro Takemasa, Pieter Tanis, Jared Torkington, Jurriaan Tuynman, Elena Vikis, Janindra

Warusavitarne, Mark Whiteford, Hongwei Yao, Seong Hyeon Yun, Zhongtao Zhang, Minhua Zheng

\section{Research support:}

Prof. Jos Kleijnen (Maastricht University, Netherlands), Guideline methodologist

Marta Penna(Imperial College, London, UK), Clinical Research Fellow

\section{Correspondence:}

Roel Hompes, MD, PhD

Department of Surgery, Amsterdam University Medical Centres - location AMC

University of Amsterdam

Meibergdreef 9, 1105 AZ Amsterdam, The Netherlands

Email: r.hompes@amc.uva.nl

Tel: $+\underline{3120-5662660}$

Keywords: TaTME, TME, rectal surgery, rectal cancer, consensus, guidance

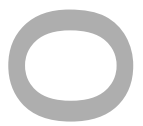

\section{Conflict of Interest Declaration:}

None of the co-authors/participants have any direct conflict of interest with regards to this paper. The participants below declare the following commitments/financial disclosures:

- Teresa deBeche-Adams - Applied Medical Honoraria for TaTME courses

- Andre D'Hoore- Educational grant from Olympus nv.

- Julian Hayes - Applied Medical Honoraria for TaTME courses and proctorship

- Alexander Heriot - Teaching on industry supported TaTME courses

- Roel Hompes - Applied Medical and Conmed honorarium for lectures and TaTME courses

- Danilo Miskovic - Honoraria from Medtronic to teach TaTME within the UK national training programme 
- Isacco Montroni - OLYMPUS SE Europe, Invited speaker at TaTME courses

- Antonino Spinelli - Ethicon and Frankenman honoraria

- Patricia Sylla - Consultant (for honorarium) with the following companies: Karl Storz, Olympus, Safeheal, Medtronic, Ethicon and Boston Scientific. Multicenter TaTME trial (US and Canada) receives grant support from: Karl Storz, Stryker, Intuitive, Ethicon, Conmed, Ethicon and Medtronic

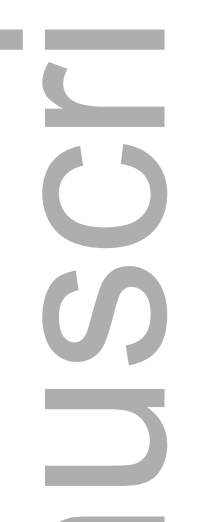

\section{Abstract}

$\underline{\text { Aim }}$

To provide dynamic guidance from a rigorous and up-to-date consensus on the safe implementation and application of TaTME from an international panel of expert surgeons and educationalists supported by 14 international surgical societies.

\section{Method}

An adapted Delphi method and focus group discussion approach was implemented for this consensus process with expert advice from a guidelines methodologist. Statements were generated focusing on three main topics related to the safe TaTME implementation: (1) indications, (2) quality and outcome measures, (3) training and implementation of TaTME. $\underline{\text { Results }}$

Five rounds of the Delphi consensus process were completed over a thirteen-month period. A total of 56 surgeons experienced in TaTME and surgical education participated in this project. By Delphi round $4, \geq 80.0 \%$ agreement was reached for all statements except for two, which were further reviewed during a $5^{\text {th }}$ round. More complex cases that are likely to benefit from TaTME were identified with the recommendation that they should be referred to TaTME expert centres. The most agreed upon definition of expert centres is outlined. $\underline{\text { Conclusion }}$ 
We have provided a current framework of best practice related to implementation of TaTME. The statements are not indefinite and will continue to be 'dynamic' and updated as new evidence emerges.

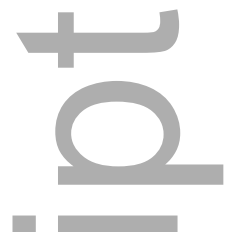

What does this paper add to the literature?

A new adapted Delphi consensus method that has engaged international expertise and collaboration in order to provide more detailed guidance on the safe adoption and practice of TaTME.

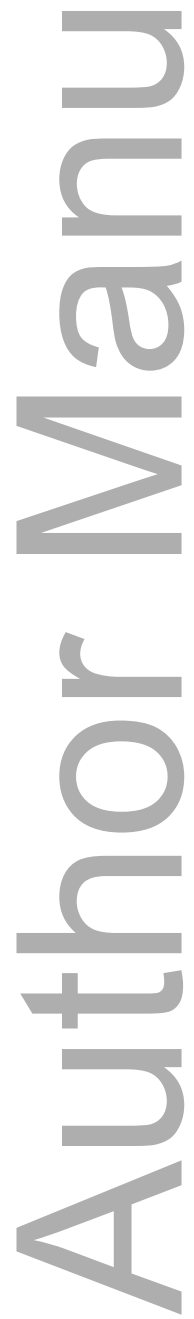

\section{Introduction}


The introduction of transanal total mesorectal excision (TaTME), following initial positive reports on the feasibility of this method [1-4] was largely unregulated and unstructured. Although steps were taken to follow the IDEAL recommendations for surgical innovation [5], the technique moved rapidly from the translational (early adopters) to the explorative phase (larger surgical community) [6-10]. The concept of accessing the notoriously difficult anatomical environment of the lower pelvis through the anus offered a seemingly logical and innovative solution to optimize safe resection margins during rectal cancer surgery. Subsequently, indications were expanded to other fields, such as transanal proctectomy for inflammatory bowel disease and management of chronic pelvic sepsis following failed colorectal anastomoses [11-13]. While published data on short-term oncological outcomes from the international LOREC TaTME registry have been non-inferior to that of laparoscopic or open TME [14], a recent report on high rates of multifocal pelvic recurrences in a cohort in Norway has led to serious concerns regarding the oncological safety of TaTME and resulted in a moratorium in that country until further robust data is available $[15,16]$. Previous reports on technique-specific complications, such as urethral injuries and $\mathrm{CO}_{2}$ embolism, have also raised concerns regarding the procedural safety of the procedure $[8,14,17,18]$. It remains unclear whether these issues are related to poor adherence to recommendations regarding safe adoption and performance of TaTME, including insufficient procedural training, lack of prerequisite technical skills, or inappropriate patient selection. Recent data highlighting the long learning curve required to master TaTME, even by experts, has led to the debate as to whether this technique can be safely implemented outside of high-volume, tertiary referral centres for rectal cancer $[19,20]$.

More recently, a proposal was made for a structured training program specifically for TaTME [21-23] aiming for a more controlled and safer implementation by safeguarding training of surgeons with the necessary pre-requisite skills, appropriate case selection and proctoring of initial cases. A recent expert consensus statement was a further attempt to structure the safe implementation of TaTME, but it was felt that the consensus was not complete and not rigorous enough in its content [24].

The European Society of Coloproctology (ESCP) instigated a new consensus with the aim to develop guidelines regarding safe implementation and application of TaTME. Active collaboration with other colorectal societies was sought and led to this consensus guidance regarding indications and implementation with broad international support.

\section{Method}


For this expert consensus project, an adapted Delphi method and focus group discussion approach was used. A core group of 17 expert surgeons from eight countries who were either early adopters of TaTME, and/or high volume TaTME surgeons, and/or actively involved in TaTME training as workshop faculty members or proctors, and/or who had extensively published on the topic, met during the annual ESCP conference in Berlin, September 2017. Four topics related to safe TaTME implementation were identified: (1) indications, (2) quality and outcome measures, (3) training and (4) technique. Each topic was assigned a working group that was tasked with drafting expert statements and recommendations related to their assigned topic, based on review of published evidence as well as expert opinions.

A second face-to-face meeting was held in December 2017 during the European Congress of St. Gallen (Switzerland) to review the initial draft statements and further define the methodology for this consensus project. In consultation with an expert in clinical guideline development (JK), the group determined that in the absence of high-level evidence (such as randomised controlled trials), the expert panel would use a pragmatic structured expert consensus in order to provide an "International Expert Guidance on the safe implementation of TaTME" document rather than more prescriptive evidence-based, best-practice guideline on safe implementation of TaTME. The panel also agreed that a wider and more diverse group of TaTME experts should be selected from various surgical societies around the world. Consequently, additional experts were invited from the ASCRS (American Society of Colon and Rectum Surgeons), ACPGBI (Association of Coloproctology of Great Britain and Ireland), ECCO (European Crohn's and Colitis Organisation), EAES (European Association of Endoscopic Surgeons), ESSO (European Society of Surgical Oncology), CSCRS (Canadian Society of Colorectal Surgery), CNSCRS (Chinese Society of Colorectal Surgery), CSLES (Chinese Society of Laparo-Endoscopic Surgery), CSSANZ (Colorectal Surgical Society of Australia and New Zealand), JSES (Japanese Society of Endoscopic Surgery), SACP (Argentinian Society of Coloproctology), SAGES (Society of American Gastrointestinal and Endoscopic Surgeons), SBCP (Brazilian Society of Coloproctology) and the Swiss-MIS (Swiss association for Minimally Invasive Surgery).

Each working group subsequently revised the initial set of guidance statements for each of the four topics related to safe TaTME implementation. The statements were organized into an 
electronic Delphi questionnaire (SurveyMonkey®). The first round of voting was sent electronically to 50 participating surgeons with 24 responses received (48.0\%). A second round of the Delphi questionnaire was sent to the group that increased to 55 members at this point and $33(60.0 \%)$ responded.

The third meeting in-person took place in London, UK, during the EAES conference in May 2018 with some surgeons attending via an internet-based teleconference link. Results from the $2^{\text {nd }}$ round of voting were reviewed, and the guidance statements were further modified during focus group discussions. At this point, it was decided to abandon the statements regarding surgical technique (group 4). The group recognised that developing technical guidelines would require too many resources and should be explored as a separate project. After this meeting, a further round of voting $\left(3^{\text {rd }}\right)$ was carried out with the revised guidance statements with a response rate of $78.2 \%(43 / 55$ members $)$.

A fourth meeting and final face-to-face meeting was held during the ESCP conference in Nice, September 2018. Again, previous results were analysed, and comments reviewed. Further amendments were made by the group during group discussions.

The final group of expert participants consisted of 56 surgeons from 19 different countries (Argentina, Australia, Austria, Belgium, Brazil, Canada, China, England, France, Germany, Italy, Japan, Korea, New Zealand, Spain, Switzerland, The Netherlands, United States of America, Wales). The fourth round of voting was completed by $54 / 56$ members $(96.4 \%)$ following the group meeting in Nice. A final, fifth round of voting was sent to address two statements where consensus could not be reached. An 87.5\% (49/56) response rate was obtained.

Analysis

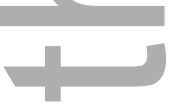

\section{Analysis}

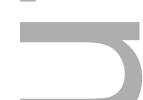

Delphi questionnaires were structured as guidance statements and consensus was assessed based on the level of agreement/disagreement for each item. Free text comments were elicited during each round of Delphi questionnaires and reviewed during focus group discussions with revision of statements at each meeting. While there was no limit on the number of rounds of reiterative questionnaires sent out, for the purpose of this guidance document, consensus was considered achieved when agreement level of $>80 \%$ was reached 


\section{Results}

Five rounds of the Delphi consensus process were completed over a thirteen-month period. A total of 56 surgeons experienced in TaTME and surgical education participated in this project. The guidance statements, level of agreement achieved, and written comments were reviewed and discussed at face-to-face meetings after the initial three rounds. By Delphi round 4, $\geq 80.0 \%$ agreement was reached for all statements except for two; indications for completion TME surgery, and definition of an expert centre. A fifth Delphi round was conducted in September 2019 in an effort to resolve both statements. A summary of the consensus process for this guidance document can be found in Table 1. Guidance statements regarding indications, surgical quality and, training and implementation of TaTME are listed in Tables 2-5 with the final levels of agreement for each statement.
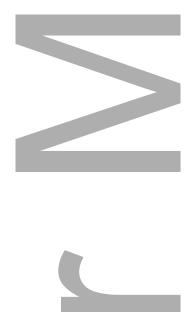

\section{Discussion and conclusions}

In the current climate of uncertainty regarding outcomes, indications and implementation of TaTME, development of guidance statements on safe adoption and implementation of TaTME have been long awaited by surgical societies and rectal cancer surgeons. Since implementation of novel surgical techniques is not usually regulated, albeit local protocols for such process may be in place [25], guidance recommendations can provide a framework for the safe introduction of TaTME [5]. These recommendations can be seen as a framework, which are a component of the development phase of the IDEAL guidance for surgical innovation. They should allow for a safer progression to the exploration phase, where the larger surgical community gets involved. 
The authors considered these statements to be timely because TaTME has been rapidly adopted globally, despite a lack of robust evidence regarding safety from multicentre randomised controlled trials, often with insufficient training and/or lack of adherence to recommendations regarding appropriate indications or best practices [8]. This has led directly and unnecessarily to high rates of adverse clinical events. Reports on unusual complications, such as urethral injuries and, more recently, $\mathrm{CO}_{2}$ embolism have raised significant concerns in the surgical community $[14,17,18]$. Concerns regarding unexpected high rates of multifocal cancer recurrence, despite being isolated, have led to a national moratorium for TaTME in Norway and other units in different countries abandoning the technique for similar concerns $[15,16]$.

In generating guidance statements regarding indications of TaTME, agreement was the most difficult to reach. Disagreement on the wording and definitions became apparent e.g. in statement 4 on TaTME approach 'guaranteeing' a clear distal margin, which was criticised by some who felt that a clear margin can never be guaranteed. Technical difficulties completing TME with an abdominal approach (statement 1) could not be further defined and it was recognised that such difficulties cannot always be predicted preoperatively, and the choice of approach may be changed intraoperatively ('conversion to TaTME'). Some experts also wanted to include partial mesorectal excisions (PME) as an indication for a transanal approach, but a majority supported the notion that, in cancer, a transanal approach should only be considered when TME is indicated (statement 3). However, it was acknowledged that in specific circumstances, when an abdominal approach was deemed hazardous due to tumour size or anatomical constraints, TaTME should be considered for PME.

A number of statements on specific indications for TaTME relied on the prerequisite that procedures should be performed in expert centres. Reaching consensus on the definition of an expert centre was difficult and several revisions were required. Some of the supporting organisations disagree at society level with the final consensus on expert centres agreed by the participants.

Guidance statements regarding the quality and outcome measures for TaTME included strong recommendations regarding the need for prospective clinical audits of TaTME outcomes. Some authors expressed concerns that in some cases this would require resources that may not be available in all units. In other countries, national mandatory databases for colorectal cancer are already in place and met the criteria for clinical auditing. 
Assessing the TaTME learning curve using negative clinical outcomes such as complication rates and/or incomplete resections is ethically very problematic as it demonstrates the inability of a surgeon to perform a procedure safely during the early phase of the learning curve. Hence, efforts should be directed towards the implementation of mechanisms that mitigate the risk of negative patient outcomes during surgeons' skill acquisition phases. The guidance statements regarding taTME training and implementation include the strict requirement for workshops and proctoring including a formative assessment framework (statements 19 and 24). Detailed structure and content of workshops was outlined, including the need for careful case selection in the early learning phase (statements 20 and 22). These requirements currently exceed available resources in most countries, albeit some examples show that such training programmes are feasible and effective [21-23]. Nevertheless, for a majority of surgeons who wish to initiate TaTME, these programmes are not accessible and there is a clear need to develop these structured training programs globally. The debate regarding formulating a guidance statement on the minimum volume of rectal cancer surgery required at institutional level, highlighted major differences in centralization of rectal cancer care, regional patterns of cancer referral, and strong opinions regarding how proficiency should be defined. A minimum number of 30 rectal cancer cases per year reached the highest level of agreement (statement 16). Although the recommendation that at least two surgeons should be trained per hospital reached consensus (statement 17), some experts mentioned that in some circumstances, a single surgeon may be sufficient, and that some centres may not support synchronous operating due to limited resources.

This guidance document is based on a consensus process representing expert opinion, due to lack of high-quality evidence to support many of the recommendations. While this may be seen as a major limitation of the document, these statements are not indefinite and may evolve based on emerging evidence. The intent of this document was to provide a current framework of best practices related to implementation of TaTME, that will subsequently be updated to reflect new evidence as it emerges.

\section{Acknowledgments}


We would like to thank Professor Jos Kleijnen, Professor of Systematic Reviews and Clinical Guidelines from the School for Public Health and Primary care (CAPRHI) at Maastricht University (The Netherlands) for his invaluable input and advise during the development of this guidance statement paper.

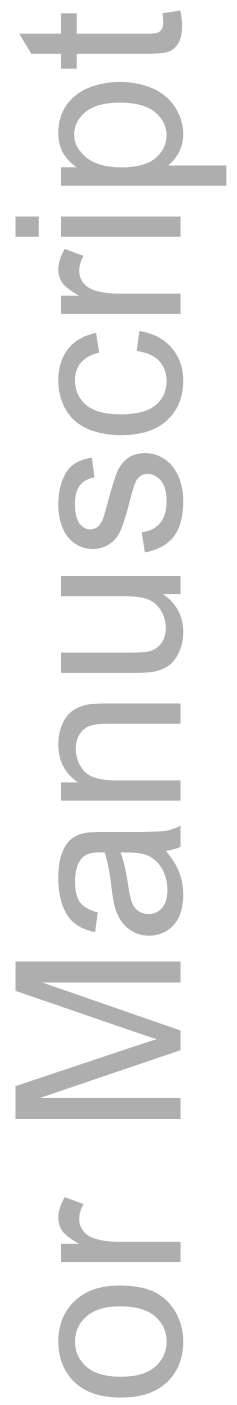

\section{References}

1. Sylla P, Willingham FF, Sohn DK, Gee D, Brugge WR, Rattner DW. (2008) NOTES rectosigmoid resection using transanal endoscopic microsurgery (TEM) with transgastric endoscopic assistance: a pilot study in swine. J Gastrointest Surg, 12(10):1717-1723.

2. Trunzo JA, Delaney CP. (2010) Natural orifice proctectomy using a transanal endoscopic microsurgical technique in a porcinemodel. Surg Innov, 17(01):48-52.

3. Telem DA, Han KS, Kim MC, et al. (2013) Transanal rectosigmoid resection via natural orifice translumenal endoscopic surgery (NOTES) with total mesorectal excision in a large human cadaver series. Surg Endosc, 27(01):74-80. 
4. Sylla P, Rattner DW, Delgado S, Lacy AM. (2010) NOTES transanal rectal cancer resection using transanal endoscopic microsurgery and laparoscopic assistance. Surg Endosc, 24(05):1205-1210

5. McCulloch P, Altman DG, Campbell WB et al. (2009) Balliol Collaboration. No surgical innovation without evaluation: the IDEAL recommendations. Lancet, 374:1105-1112

6. Hompes R, Arnold S, Warusavitarne J. (2014) Towards the safe introduction of transanal total mesorectal excision: the role of a clinical registry. Colorectal Dis, 16:498-501

7. Penna M, Whiteford M, Hompes R, Sylla P. (2017) Developing and assessing a cadaveric training model for transanal total mesorectal excision: initial experience in the UK and USA. Colorectal Disease, 19(5):476-484. doi: 10.1111/codi.13525.

8. Atallah SB, DuBose AC, Burke JP, Nassif G, deBeche-Adams T, Frering T, Albert MR, Monson JRT. (2017) Uptake of Transanal Total Mesorectal Excision in North America: Initial Assessment of a Structured Training Program and the Experience of Delegate Surgeons. Dis Colon Rectum, 60(10):1023-1031.

9. Lacy AM, Tasende MM, Delgado S, Fernandez-Hevia M, Jimenez M, De Lacy B, Castells A, Bravo R, Wexner SD, Heald RJ. (2015) Transanal Total Mesorectal Excision for Rectal Cancer: Outcomes after 140 Patients. J Am Coll Surg., 221(2):415-23.

10. Penna M, Hompes R, Arnold S, et al.; International TaTME Registry Collaborative. (2019) Incidence and Risk Factors for Anastomotic Failure in 1594 Patients Treated by Transanal Total Mesorectal Excision: Results From the International TaTME Registry. Ann Surg, 269:700-11.

11. Leo CA, Samaranayake S, Perry-Woodford ZL, et al. (2016) Initial experience of restorative proctocolectomy for ulcerative colitis by transanal total mesorectal rectal excision and single-incision abdominal laparoscopic surgery. Colorectal Dis., 18(12):11621166. doi: $10.1111 /$ codi.13359.

12. Zaghiyan K, Warusavitarne J, Spinelli A, Chandrasinghe P, Di Candido F, Fleshner P. (2018) Technical variations and feasibility of transanal ileal pouch-anal anastomosis for ulcerative colitis and inflammatory bowel disease unclassified across continents. Tech Coloproctol., 22(11):867-873.

13. Dapri G, Guta D, Grozdev K, Antolino L, Bachir N, Jottard K, Cadière GB. (2016) Colorectal anastomotic leakage corrected by transanal laparoscopy. Colorectal Dis., 18(6):0210-3. doi: $10.1111 /$ codi.13358.

This article is protected by copyright. All rights reserved 
14. Penna M, Hompes R, Arnold S, Wynn G, Austin R, Warusavitarne J, et al.; TaTME Registry Collaborative. (2017) Transanal Total Mesorectal Excision: International Registry Results of the First 720 cases. Ann Surg., 266(1):111-117.

15. Larsen SG, Pfeffer F, Kørner H; Norwegian Colorectal Cancer Group. (2019) Norwegian moratorium on transanal total mesorectal excision. Br J Surg., 106(9):1120-1121. doi: 10.1002/bjs.11287.

16. Wasmuth HH, Faerden AE, Myklebust TÅ, et al. (2020) Transanal total mesorectal excision for rectal cancer has been suspended in Norway. Br J Surg., 107(1):121-130.

17. Dickson EA, Penna M, Cunningham C, et al. International TaTME Registry Collaborative. (2019) Carbon Dioxide Embolism Associated With Transanal Total Mesorectal Excision Surgery: A Report From the International Registries. Dis Colon Rectum, 62(7):794-801.

18. Harnsberger CR, Alavi K, Davids JS, Sturrock PR, Zayaruzny M, Maykel JA. (2018) $\mathrm{CO}_{2}$ embolism can complicate transanal total mesorectal excision. Tech Coloproctol., 22(11):881-885. doi: 10.1007/s10151-018-1897-8. Epub 2018 Dec 6.

19. Lee L, Kelly J, Nassif GJ, deBeche-Adams TC, Albert MR, Monson JRT. (2018) Defining the learning curve for transanal total mesorectal excision for rectal adenocarcinoma. Surg Endosc. Jul 11. doi: 10.1007/s00464-018-6360-4. [Epub ahead of print]

20. Koedam TWA, Veltcamp Helbach M, van de Ven PM, et al. (2018) Transanal total mesorectal excision for rectal cancer: evaluation of the learning curve. Tech Coloproctol., 22(4):279-287. doi: 10.1007/s10151-018-1771-8. Epub 2018 Mar 22.

21. Francis N, Penna M, Mackenzie H, Carter F, Hompes R; International TaTME Educational Collaborative Group. (2017) Consensus on structured training curriculum for transanal total mesorectal excision (TaTME). Surg Endosc, 31:2711-9.

22. Veltcamp Helbach M, van Oostendorp SE, Koedam TW, et al. (2019) Structured training pathway and proctoring; multicenter results of the implementation of transanal total mesorectal excision (TaTME) in the Netherlands. Surg Endosc , Mar 19. doi: 10.1007/s00464-019-06750-w. [Epub ahead of print].

23. Abbott, S., Stevenson, A., Bell, S., Clark, D., Merrie, A., Hayes, J., Ganesh, S., Warrier, S. (2018) An assessment of an Australasian pathway for the introduction of transanal total mesorectal excision (taTME). Colorectal Disease, 20(1), 01-06.

This article is protected by copyright. All rights reserved 
24. Adamina M, Buchs NC, Penna M, Hompes R; St.Gallen Colorectal Consensus Expert Group. (2018) St.Gallen consensus on safe implementation of transanal total mesorectal excision. Surg Endosc., 32(3):1091-1103.

25. National Institute for Health and Care Excellence (2015) Transanal total mesorectal excision of the rectum. Interventional procedure guidance. Available at http://nice.org.uk/guidance/ipg514. Accessed $8^{\text {th }}$ January 2020.

Tables

Table 1. Summary of the guidance statement development process. N/A: non-applicable.

\begin{tabular}{|c|c|c|c|}
\hline Date & Type & Comments & $\begin{array}{c}\text { Average } \\
\text { agreement level } \\
\%\end{array}$ \\
\hline September 2017 & Focus group (Berlin) & $\begin{array}{l}\text { Defining purpose and } \\
\text { subjects, formation of } \\
\text { working-groups }\end{array}$ & N/A \\
\hline December 2017 & $\begin{array}{l}\text { Focus group (St } \\
\text { Gallen) }\end{array}$ & $\begin{array}{l}\text { Determining methodology, } \\
\text { initial guidance statements }\end{array}$ & $\mathrm{N} / \mathrm{A}$ \\
\hline May 2018 & Delphi round 1 & Participation $24 / 50(48 \%)$ & 81.9 \\
\hline May 2018 & Delphi round 2 & Participation 33/55 (60\%) & 78.8 \\
\hline May 2018 & Focus group (London) & $\begin{array}{l}\text { Reviewing and adapting } \\
\text { previous statements }\end{array}$ & N/A \\
\hline August 2018 & Delphi round 3 & $43 / 55(78.2 \%)$ & 84.2 \\
\hline September 2018 & Focus group (Nice) & $\begin{array}{l}\text { Reviewing and adapting } \\
\text { previous statements }\end{array}$ & $\mathrm{N} / \mathrm{A}$ \\
\hline October 2018 & Delphi round 4 & $\begin{array}{l}\text { Participation } 54 / 56 \\
(96.4 \%)\end{array}$ & 91.3 \\
\hline
\end{tabular}




\begin{tabular}{|l|l|l|c|}
\hline June 2019 & Delphi round 5 & $\begin{array}{l}\text { Selected statements only } \\
\text { Definition of expert centre }\end{array}$ & 70.8 \\
\hline
\end{tabular}

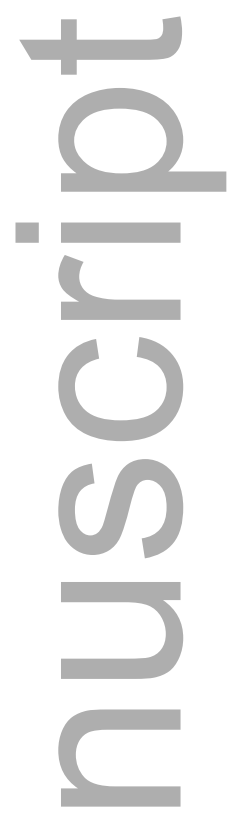

Table 2. Guidance statements on indications for TaTME

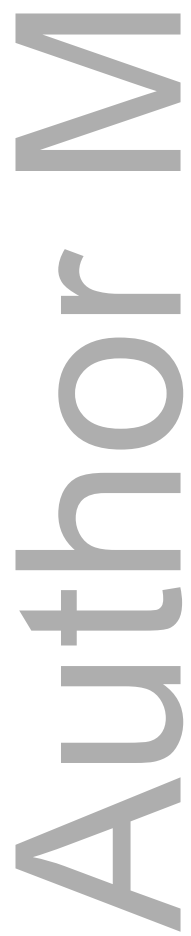




\begin{tabular}{|c|c|c|}
\hline No & Guidance statements: Indications for TaTME & Agreement \\
\hline 1 & $\begin{array}{l}\text { A transanal approach could be used for any benign or malignant rectal resection where } \\
\text { there is anticipated technical difficulty in pelvic dissection. }\end{array}$ & $93.40 \%$ \\
\hline 2 & $\begin{array}{l}\text { Patients with previous prostatectomy, previous pelvic radiation (other than neoadjuvant } \\
\text { treatment) or previous complex pelvic surgery can be considered for TaTME but the } \\
\text { operation should only be performed in expert centres. }\end{array}$ & $98.40 \%$ \\
\hline 3 & $\begin{array}{l}\text { Transanal total mesorectal excision (TaTME) should be used in rectal cancers only when } \\
\text { total mesorectal excision is indicated. }\end{array}$ & $80.30 \%$ \\
\hline 4 & $\begin{array}{l}\text { A transanal approach should be recommended in rectal cancer patients where a clear } \\
\text { distal margin cannot be guaranteed by a pure abdominal approach. }\end{array}$ & $90.20 \%$ \\
\hline 5 & $\begin{array}{l}\text { cT4 and Rullier Type } 3 \text { intra-anal rectal cancers can be considered for a transanal approach } \\
\text { but should only be performed in expert centres. }\end{array}$ & $83.60 \%$ \\
\hline 6 & $\begin{array}{l}\text { A transanal approach could be used if completion TME is indicated after previous full } \\
\text { thickness local excision. }\end{array}$ & $77.6 \%$ \\
\hline 7 & $\begin{array}{l}\text { A transanal approach could be recommended for completion proctectomy in } \\
\text { inflammatory bowel disease. }\end{array}$ & $95.10 \%$ \\
\hline 8 & $\begin{array}{l}\text { In both inflammatory bowel disease (IBD) and familial adenomatous polyposis (FAP) } \\
\text { patients, a transanal approach should be recommended for an ileoanal pouch procedure } \\
\text { where there is anticipated difficulty in judging the level of distal transection by a pure } \\
\text { abdominal approach. }\end{array}$ & $86.90 \%$ \\
\hline 9 & $\begin{array}{l}\text { A transanal approach can be considered for revision of an ileoanal pouch but should only } \\
\text { be performed in expert centres. }\end{array}$ & $95.10 \%$ \\
\hline 10 & $\begin{array}{l}\text { A transanal approach for revision of refractory anastomosis-related sepsis can be } \\
\text { considered but should only be performed in expert centres. }\end{array}$ & $96.70 \%$ \\
\hline
\end{tabular}

This article is protected by copyright. All rights reserved 


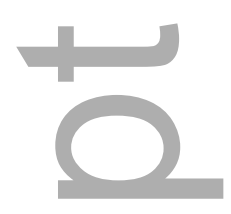

Table 3. Guidance statements on surgical quality of TaTME

\begin{tabular}{|l|l|l|}
\hline No & Guidance statements: Surgical quality of TaTME & Agreement \\
\hline 11 & $\begin{array}{l}\text { An institutional protocol for TaTME must be established including operative set-up, } \\
\text { procedural guide and perioperative management of the patient. }\end{array}$ & $93.30 \%$ \\
\hline 12 & $\begin{array}{l}\text { TaTME histopathological and oncological outcomes must be prospectively recorded } \\
\text { include specimen quality, circumferential resection margin (CRM), distal resection } \\
\text { margin (DRM), local recurrence rates, disease-free survival and overall survival. }\end{array}$ & $90.00 \%$ \\
\hline 13 & $\begin{array}{l}\text { TaTME surgical outcome measures must be prospectively recorded and } \\
\text { benchmarked against the institution's historical performance. These must include } \\
\text { operative time, intra-operative adverse events, conversion rates, post-operative } \\
\text { morbidity and long-term anastomotic failure rate. }\end{array}$ & $85.00 \%$ \\
\hline 14 & $\begin{array}{l}\text { TaTME functional outcomes could be prospectively recorded. These could include } \\
\text { questionnaires on general and disease-specific quality of life, bowel, urinary and } \\
\text { sexual function. }\end{array}$ & $85.00 \%$ \\
\hline
\end{tabular}


Table 4. Guidance statements on implementation and training of TaTME

\begin{tabular}{|c|c|c|}
\hline No & Guidance statements: Implementation and Training & Agreement \\
\hline 15 & $\begin{array}{l}\text { A formal structured training pathway should be completed to safely implement } \\
\text { TaTME into clinical practice. }\end{array}$ & $95.00 \%$ \\
\hline 16 & $\begin{array}{l}\text { The recommended requirements before undertaking a structured training pathway } \\
\text { in TaTME must include established experience in minimally invasive TME and an } \\
\text { annual institutional volume of at least } 30 \text { rectal resections. }\end{array}$ & $91.70 \%$ \\
\hline 17 & $\begin{array}{l}\text { TaTME should be implemented by at least two surgeons per institution who have } \\
\text { completed structured training. }\end{array}$ & $90.00 \%$ \\
\hline 18 & $\begin{array}{l}\text { TaTME should be implemented within a multidisciplinary dedicated operative } \\
\text { theatre team. }\end{array}$ & $91.70 \%$ \\
\hline 19 & $\begin{array}{l}\text { A structured TaTME training curriculum should include (i) didactic learning, (ii) } \\
\text { observation of live TaTME procedures, including theatre set up, (iii) a hands-on } \\
\text { cadaver workshop, and (iv) a formal proctorship programme. }\end{array}$ & $95.00 \%$ \\
\hline 20 & $\begin{array}{l}\text { The didactic learning contents must include (i) patient selection, (ii) pelvic, perineal } \\
\text { and transanal anatomy, (iii) operative setup, techniques, and detailed procedural } \\
\text { steps, (iv) strategies to avoid and manage procedural difficulties and complications, } \\
\text { and (v) practical steps of how to implement the technique into clinical practice. }\end{array}$ & $96.70 \%$ \\
\hline 21 & $\begin{array}{l}\text { Clinical training (proctorship) on TaTME should commence as early as possible after } \\
\text { attending the cadaveric workshop with assigned proctors. }\end{array}$ & $98.30 \%$ \\
\hline 22 & Case selection must be discussed with the proctor. & $96.70 \%$ \\
\hline 23 & $\begin{array}{l}\text { Proctorship training should continue until safe independent performance is } \\
\text { achieved. }\end{array}$ & $93.30 \%$ \\
\hline 24 & $\begin{array}{l}\text { Formative assessment (e.g. Global Assessment Score - GAS forms) should be } \\
\text { applied during the entire length of the proctorship to monitor learning and to guide } \\
\text { the duration of proctorship. }\end{array}$ & $93.30 \%$ \\
\hline 25 & $\begin{array}{l}\text { Regular review and evaluation of clinico-pathological data with proctor feedback } \\
\text { during the implementation phase must be carried out. Data should be collected in } \\
\text { an established TaTME registry. }\end{array}$ & $93.30 \%$ \\
\hline
\end{tabular}

This article is protected by copyright. All rights reserved 


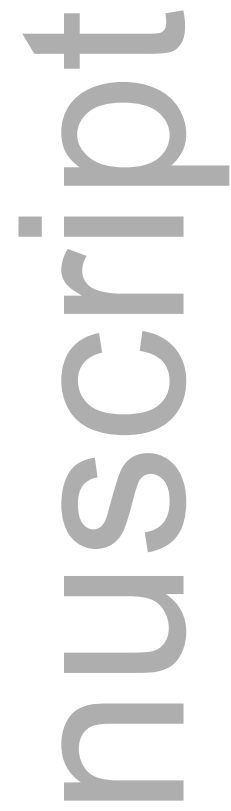

Table 5. Definition of expert centres
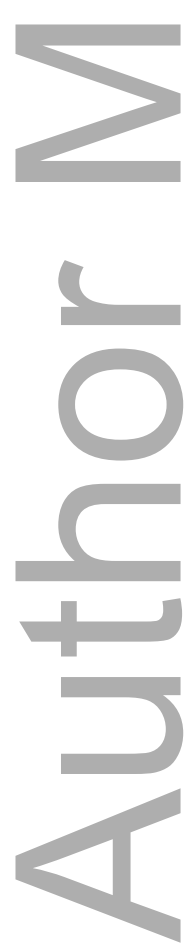

This article is protected by copyright. All rights reserved 


\begin{tabular}{|c|c|c|}
\hline No & Definition of expert centres & Agreement \\
\hline 1 & $\begin{array}{l}\text { CENTRE SPECIFICATIONS: } \\
\text { i) Established tertiary referral centre for rectal cancer } \\
\text { ii) Centre for transanal and transabdominal minimally invasive surgery } \\
\text { iii) Established multidisciplinary team } \\
\text { iv) Intensive care unit available } \\
\text { v) A minimum of } 25 \text { annual cancer resections by TaTME following the } \\
\text { indications described above; ideally reaching }>40 \text { annual resections involving } \\
\text { the rectum for benign and/or malignant disease }\end{array}$ & $62.5 \%$ \\
\hline 2 & $\begin{array}{l}\text { SURGEON EXPERTISE: } \\
\text { i) At least two GI specialist surgeons } \\
\text { ii) At least one GI surgeon with expertise in TaTME (overcome their learning } \\
\text { curve) } \\
\text { iii) Experience in intersphincteric dissection } \\
\text { iv) Surgeon contribution to TaTME training preferable (e.g. course faculty, } \\
\text { proctoring, fellowships) }\end{array}$ & $97.9 \%$ \\
\hline 3 & $\begin{array}{l}\text { CENTRE PERFORMANCE/OUTCOMES: } \\
\text { i) }>75 \% \text { of primary rectal cancer }(\leq \mathrm{T} 3) \text { performed with minimally invasive } \\
\text { surgery } \\
\text { ii) High standard of clinical and pathological outcomes when compared to } \\
\text { registry data }\end{array}$ & $91.7 \%$ \\
\hline
\end{tabular}




\section{University Library}

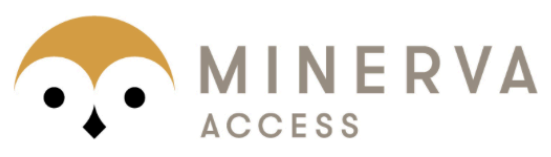

A gateway to Melbourne's research publications

Minerva Access is the Institutional Repository of The University of Melbourne

Author/s:

TaTME Guidance Group representing the ESCP (European Society of Coloproctology), in collaboration with the ASCRS (American Society of Colon and Rectal Surgeons), ACPGBI (Association of Coloproctology of Great Britain and Ireland), ECCO (European Crohn's and Colitis Organisation), EAES (European Association of Endoscopic Surgeons), ESSO (European Society of Surgical Oncology), CSCRS (Canadian Society of Colorectal Surgery), CNSCRS (Chinese Society of Colorectal Surgery), CSLES (Chinese Society of Laparo-Endoscopic Surgery), CSSANZ (Colorectal Surgical Society of Australia and New Zealand), JSES (Japanese Society of Endoscopic Surgery), SACP (Argentinian Society of Coloproctology), SAGES (Society of American Gastrointestinal and Endoscopic Surgeons), SBCP (Brazilian Society of Coloproctology), Swiss-MIS (Swiss Association for Minimally Invasive Surgery),

Title:

International expert consensus guidance on indications, implementation and quality measures for transanal total mesorectal excision.

Date:

2020-07

\section{Citation:}

TaTME Guidance Group representing the ESCP (European Society of Coloproctology), in collaboration with the ASCRS (American Society of Colon and Rectal Surgeons), ACPGBI (Association of Coloproctology of Great Britain and Ireland), ECCO (European Crohn's and Colitis Organisation), EAES (European Association of Endoscopic Surgeons), ESSO (European Society of Surgical Oncology), CSCRS (Canadian Society of Colorectal Surgery), CNSCRS (Chinese Society of Colorectal Surgery), CSLES (Chinese Society of Laparo-Endoscopic Surgery), CSSANZ (Colorectal Surgical Society of Australia and New Zealand), JSES (Japanese Society of Endoscopic Surgery), SACP (Argentinian Society of Coloproctology), SAGES (Society of American Gastrointestinal and Endoscopic Surgeons), SBCP (Brazilian Society of Coloproctology), Swiss-MIS (Swiss Association for Minimally Invasive Surgery), (2020). International expert consensus guidance on indications, implementation and quality measures for transanal total mesorectal excision.. Colorectal Dis, 22 (7), pp.749-755. https://doi.org/10.1111/codi.15147.

Persistent Link: 
